\title{
Limb apraxia in patients with damage confined to the left basal ganglia and thalamus
}

\author{
E DE RENZI, P FAGLIONI, M SCARPA, G CRISI \\ From the Departments of Neurology and Radiology, University of Modena, Italy
}

SUMMARY Limb apraxia was investigated with standardised tests in 14 patients whose CT scan provided evidence of a vascular lesion confined to the left basal ganglia, or the thalamus, or both, and not involving the cortex or adjacent white matter. Five patients were severely impaired in imitating movements and pantomiming object use. Four of them also performed poorly when tested with real objects. In two patients the lesion was primarily thalamic and in three the lesion was primarily in the lenticular nucleus and the posterior limb of the internal capsule. Patients without apraxia generally had smaller injuries, but there were exceptions. Apraxia is currently conceived of as due to damage of cortical areas and their cortico-cortical connections, but the present data suggest that the model should be enlarged to include the deep nuclei and the pathways running through them.

The introduction of CT examination in neurological practice has opened new avenues to the understanding of the anatomical basis of higher nervous function disorders. On the basis of CT results, it has been discovered that deep hemispheric structures, play a hitherto unsuspected role in the genesis of symptoms that were thought to be the province of the neocortex and the underlying white matter. Depending on the side of lesion, aphasia ${ }^{1-6}$ and unilateral neglect ${ }^{127-10}$ have been reported to result from damage restricted to the striatum, or the thalamus, or both, suggesting that the circuits subserving language and lateral attention must be enlarged to include these structures. No comparable evidence has hitherto been reported for apraxia, a condition traditionally attributed to the involvement of parietal and frontal cortical areas of the hemisphere dominant for speech and/or to the fibre bundles connecting them within the same hemisphere and through the corpus callosum with the premotor cortex of the contralateral hemisphere. ${ }^{11-14}$

Our interest in the relationship between left deep nuclei damage and movement organisation disorders was first aroused by a patient who had severe limb apraxia following a haematoma shown by CT scan to

Received 25 June 1985 and in revised form 28 October 1985. Accepted 2 November 1985

Address for reprint requests: Dr E De Renzi, Clinica Neurologica, Via Del Pozzo 71, Modena 41100, Italy. involve the left thalamus, the posterior limb of the internal capsule and the posterior part of the lenticular nucleus. Alerted by this case, we searched the files of left brain-damaged patients examined with apraxia tests in the course of previous studies and for whom there was CT scan documentation that the lesion was confined to the deep nuclei, sparing the cortex and the underlying white matter. Fourteen such cases (inclusive of the one originally examined) were recovered; in five of them there was unequivocable evidence of limb apraxia. We report in detail the five positive cases and contrast them with those not showing apraxia.

\section{Methods}

The 14 patients of the present study were, with one exception, admitted to the wards in the early days of their disease and were tested for apraxia within 10 to 50 days of the onset of their illness. They were all alert and cooperative at the time of testing. Four patients had a haematoma and 10 had a softening of the left hemisphere in an area between the wall of the third ventricle medially and the external capsule laterally.

Lesion sites were assessed with CT scan sections at $0^{\circ}$ to the canthomeatal line. In describing the lesion we will make reference to the three sections where the basal ganglia are represented (Sections 10, 9 and 8 of Matsui and Hirano's Atlas $^{15}$ ) and will designate them as the inferior, middle and superior section, respectively.

Praxis evaluation was based on the performance on a movement imitation test and an object use pantomime test 
(the latter was not given to three patients who showed no signs of apraxia).

The movement imitation test ${ }^{16}$ required the patient to reproduce with the hand ipsilateral to the lesion 24 movements (half meaningful and half meaningless) carried out by the examiner in front of him. If the reproduction was faulty, a second and, if necessary, a third trial was administered. A score of 3 (correct on first trial), 2 (correct on second trial), 1 (correct on third trial), 0 (incorrect after three attempts) was assigned, with a maximum score of 72 . The worst score found in 187 normal controls was 53 (the second to worst control subject's score was 56). Thus any score below 53 was considered indicative of apraxia. With a control sample of 187 subjects, the one sided content distribution free tolerance interval ${ }^{17}$ ensures, with a risk of error of less than 0.02 , that at least the $98 \%$ of the entire normal population will score at or above 53 .

The object use pantomime test requires the patient to pretend to use 20 common objects, which are shown to him one at a time, but which are not handled. Responses were scored 2 for correct use, 1 for almost correct, and 0 for clearly incorrect use. The cut-off score between an apraxic and normal performance is 32 .

In a number of patients the ability to handle a real object was also assessed, while complex actions implying the use of more than one object was tested in the first two patients only.

\section{Case reports}

Case 1 A 60-year-old right-handed woman, suffering from hypertension for three years, suddenly experienced pain and weakness in the right limbs and became progressively drowsy. Upon admission she was found to have a stiff neck and to be lethargic but arousable and lumbar puncture produced haemorrhagic fluid. There was a dense right hemiparesis with a positive Babinski reflex and global aphasia. In the subsequent days she showed a progressive improvement of consciousness and 13 days after the stroke right hemianesthesia and hemianopia were found. One month after onset her consciousness was clear and there was a moderate recovery of the right hemiparesis confined to the lower limb, while the right sensory loss and hemianopia remained dense. She tended to talk in a whisper. Aphasia was of the sensory transcortical type with poor comprehension (Token test: 10/36) and excellent repetition up to 15-syllable long sentences. The aphasic picture did not change substantially two months after onset.

Formal apraxia testing was carried out one month and two months after onset. Left arm and hand movements were examined on imitation, use of object pantomimes, actual use of objects and complex actions. Table 1 reports the maximum score obtainable on each test, the cut-off score distinguishing a normal from a pathological performance and the score achieved by the patient in the first and second examinations. On the first examination (one month postonset) the patient's performance on limb movement imitation was grossly defective, her score being 35 out of 72 . Examples of errors are as follows. Sign of $O K$ : The patient joined together the little finger and the thumb, making repeated forward movements with the three central fingers. Finger snap: She tightened her thumb between the forefinger and the middle finger and then snapped her fingers. Fist on the forehead, tip of the fingers on the lips: She put the tip of her fingers on the lips and then on the table. To give a kiss with the hand was carried out by closing the fist and touching the table with it. On pantomimes, she pretended to use a pistol by opening and closing her fist, and a pen by keeping her hand open on the sagittal plane and then moving it sideways. Her performance improved when she handled the objects, but still some gestures were totally incorrect: when given a screwdriver she repeatedly struck the table with its point, as if she wanted to dig; when given a saw, she held it horizontally and made sideways movements, as if cutting slices of bread. Complex actions were also incorrect at times, either because some parts were omitted or because the parts were inappropriately executed. For instance, when told to phone her daughter, she would pick up the receiver, bring it to her ear and then stop, in spite of urges to complete the call. The trial was repeated, prompting the number. She inserted her forefinger successively in the proper holes of the dial, but did not make any turning movement. Presented with a candle, a candlestick and a match box and told to light the candle, she picked up the candle with her left hand and, while still holding it, attempted to pull a match out of the box, which obviously was too difficult. Aided by the examiner, she finally succeeded, but repeatedly attempted to strike the match on the plastic surface of the table. On a second trial, she attempted to strike the match on the side of the box where there was no abrasive. When the match eventually caught fire, she lit the candle and laid it down on the table, ignoring the candlestick. Imitation of oral movements was correct and copying of drawings was marginally below the cut-off score. On the second examination ( 2 months after stroke) limb praxic scores improved, but were still pathological (table 1).

CT scan, performed on the day of admission, showed a haematoma on the left having its maximal extension at the inferior and middle slice, where it involved the posterior $2 / 3$ of the thalamus and of the posterior limb of the internal capsule and encroached upon the postero-superior lenticular nucleus (fig 1). Blood was present in the left ventricle. The

Table 1 Case I: Patient's scores on apraxia tests

\begin{tabular}{llll}
\hline & Cutting score & lst exam (1 month poststroke) & 2nd exam (2 months poststroke) \\
\hline Imitation & $52 / 72^{*}$ & 35 & 42 \\
Object Pantomimes & $32 / 40$ & 14 & 20 \\
Object use & $40 / 40$ & 30 & 35 \\
Oral apraxia & $12 / 24$ & 19 & 24 \\
Constructional apraxia & $15 / 20$ & 12 & - \\
\hline
\end{tabular}

*The first number is the cutting score and the second the maximum score. 

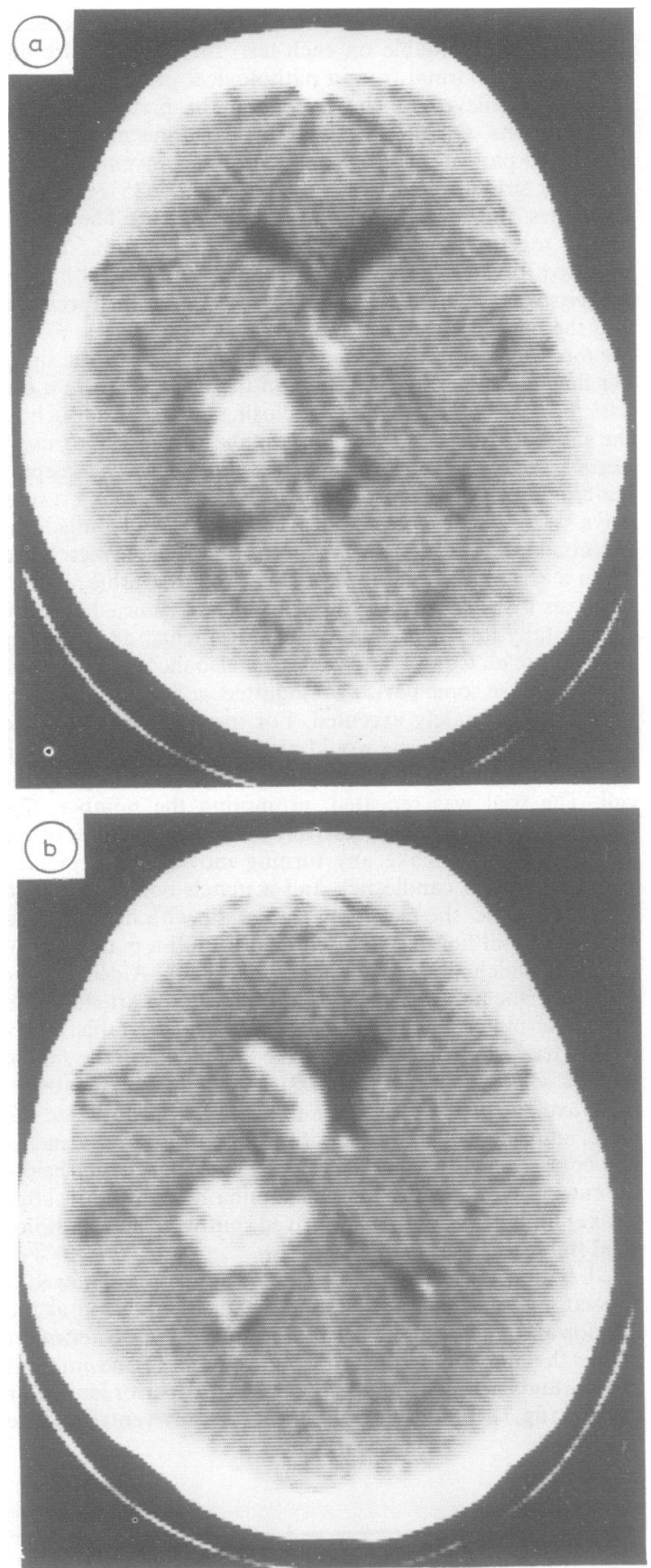

Fig 1 (Case 1). Inferior (a) and middle (b) CT scan slice showing the haematoma.

lesion was much smaller on the mesencephalic and the ventricular slice, where it abutted on the pedunculus and the periventricular white matter, respectively.
Case 2 A 72-year-old right-handed woman, with no previous history of hypertension, suddenly complained of inability to stand and of word-finding difficulty. When first examined that same day, she was found to have a mild right hemiparesis and fluent, unintelligible speech, characterised by jargon paraphasias, anomia and perseverations. She could, however, repeat non-words and long sentences. Visual fields were full, sensation was not testable. A severe apraxia on imitation was noticed. Aphasia quickly improved and 20 days later it consisted of a few anomias and semantic paraphasias, which did not prevent fairly good communication. Comprehension was only impaired for complex orders. Repetition was good.

At that time both the limb movement imitation score (26 out of 72) and the pantomime score (15 out of 40) were defective. On the latter test, the idea of the gesture could almost always be recognised, but its execution was poor, either because her hand or fingers were incorrectly positioned (for example, in pretending to use a fork she brought the closed fist to the mouth) or because she used a body part as the object, often very awkwardly. The right hand was also tested and no difference between the hands was noted. On oral movement imitation she was impaired (9 out of 24).

The patient improved remarkably when actual objects were handed for her to demonstrate their use, and was correct in carrying out complex actions, but showed a marked clumsiness in skilled motor performances (for example, when she had to screw together the two parts of a coffee machine). This awkwardness in carrying out movements requiring adroitness was directly investigated by determining the number of screws she could unscrew from a board in three minutes: she could unscrew 10 , while the mean score of 20 control subjects was 23.5 and that of 34 left brain-damaged patients was $19 \cdot 8$.

The patient was retested 9 months later. She was still severely impaired on limb movement imitation (24/72), on pantomimes (24/40) and on oral movement imitation (9/24). Token Test score was 12 out of 36 , but her language communication was fairly good.

A CT scan at 20 days after the onset of symptoms (fig 2) showed an area of decreased density in the depth of the left hemisphere, which involved most of the lenticular nucleus and the posterior limb of the internal capsule at the lower and middle slice and was still present at the upper slice as a small periventricular infarct of the white matter.

Case 3 A 51 year-old, right-handed man developed, over the course of a few hours, a dense right hemiparesis with a positive Babinski reflex and global aphasia with dysarthric speech, anomia and poor auditory comprehension. A left carotid angiography disclosed an occlusion at the origin of the Sylvian artery. The language impairment remained severe in the following days, but simple commands were understood. On visual confrontation single stimuli were perceived, but there was extinction on the right with double simultaneous stimulation. A week later he was unable to imitate any oral movement, except opening of the mouth. Imitation of gestures was grossly defective: for instance, he brought the palm of his left hand to the cheek when requested to salute and showed the first three fingers for making the sign of OK.

The limb movement imitation test was given 32 days after the stroke and yielded a clearly defective score of 25 . On 


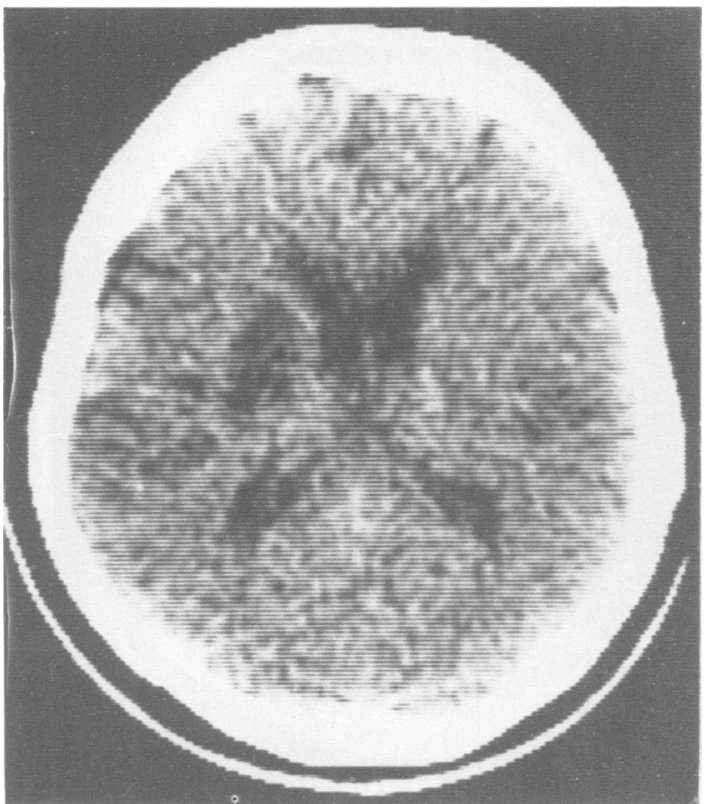

Fig 2 (Case 2). Middle CT scan slice showing the maximum extent of lesion.

object use pantomimes he scored 19 out of 40 ; when objects were handled, his performance improved, but was still in the pathological range $(34 / 40)$.

A CT scan at 18 days after the onset of symptoms showed a left-sided infarct, which at the middle slice involved the posterior part of the nucleus lenticularis and the posterior limb of the internal capsule and at the upper slice became larger and occupied the white matter adjacent to the middle third of the ventricle (fig 3 ).

Case 4 A 49-year-old right-handed man suddenly experienced right-sided hemiplegia and aphasia. The patient came to our department $\mathbf{4 5}$ days after the stroke and was found to have a dense hemiplegia and hemianaesthesia of the right limbs. Visual fields were still full and there was no suppression with double simultaneous stimulation. His speech was fluent and well-articulated, but devoid of communicative value, because of many neologisms, verbal paraphasias and perserverations. Identification by name was fair (15/20), but his Token Test score was only $12 / 36$. Repetition was preserved: he could repeat sentences of up to 18 syllables. He was cooperative but became depressed at his failures. A severe impairment in handling objects with the left hand (the only one he could move) was reported by his wife, who spontaneously noticed how awkwardly he used a fork and safety razor, and grasped a glass.

Formal tests carried out 50 days after the stroke confirmed the deficit: he scored 40 out of 72 on imitation, 5 out of 40 on pantomimes and 20 out of 40 when objects were handed to him. On pantomimes he either failed to initiate any movement, remaining perplexed as if he had forgotten the gesture, or made totally unrelated movements.

In the CT scan at 50 days after the onset of symptoms
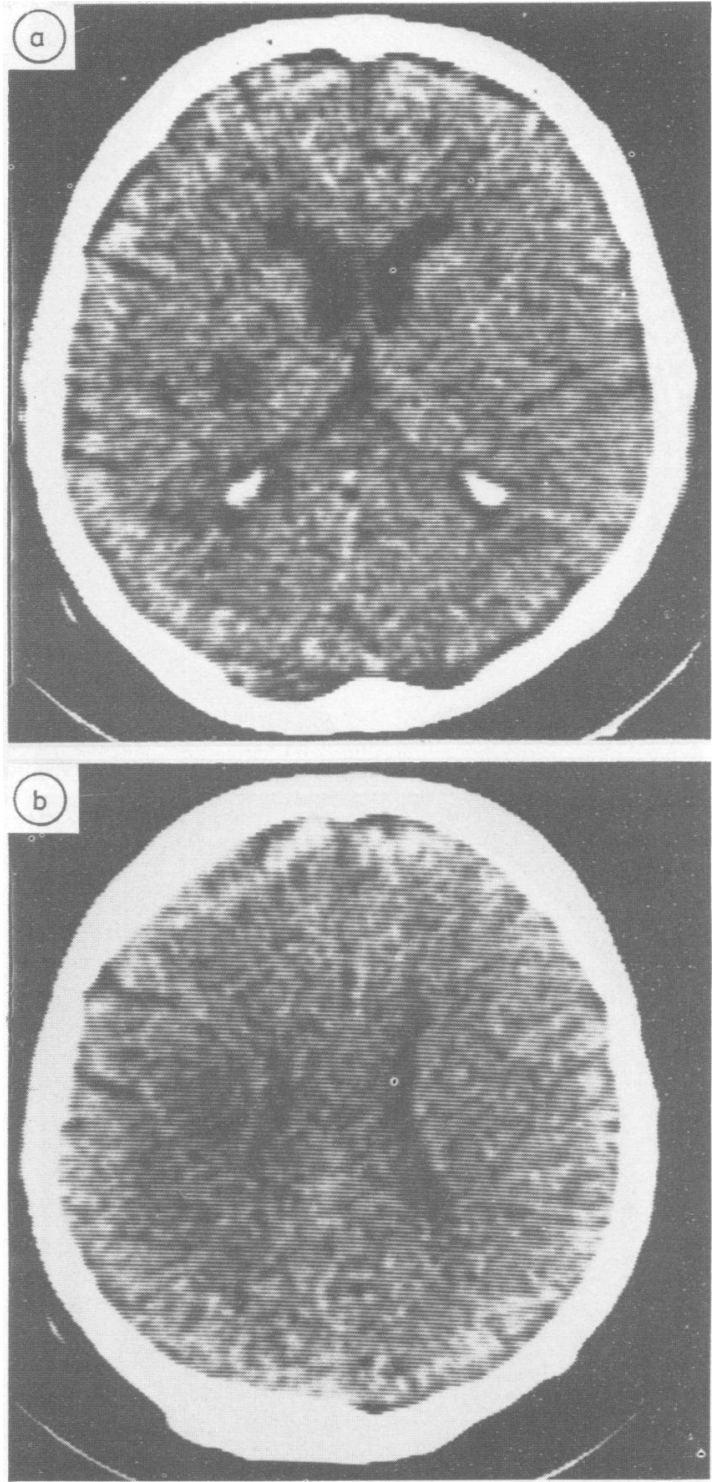

Fig 3 (Case 3). Middle (a) and upper (b) CT scan slice. The infarct involves the posterior part of the lenticular nucleus and the white matter adjacent to the left ventricle.

(fig 4) there was a left-sided infarct involving the whole territory of the deep Sylvian artery, but leaving intact the cortex and the adjacent white matter, with with the exception of the insula and the white matter of the second temporal convolution which were encroached upon in the lowest section. The lenticular nucleus, and the anterior and posterior limbs of the internal capsule were destroyed, while the head of the caudate nucleus was spared.

Case 5 A 72-year-old right-handed woman was found aphasic and hemiparetic by her relatives. At admission she 

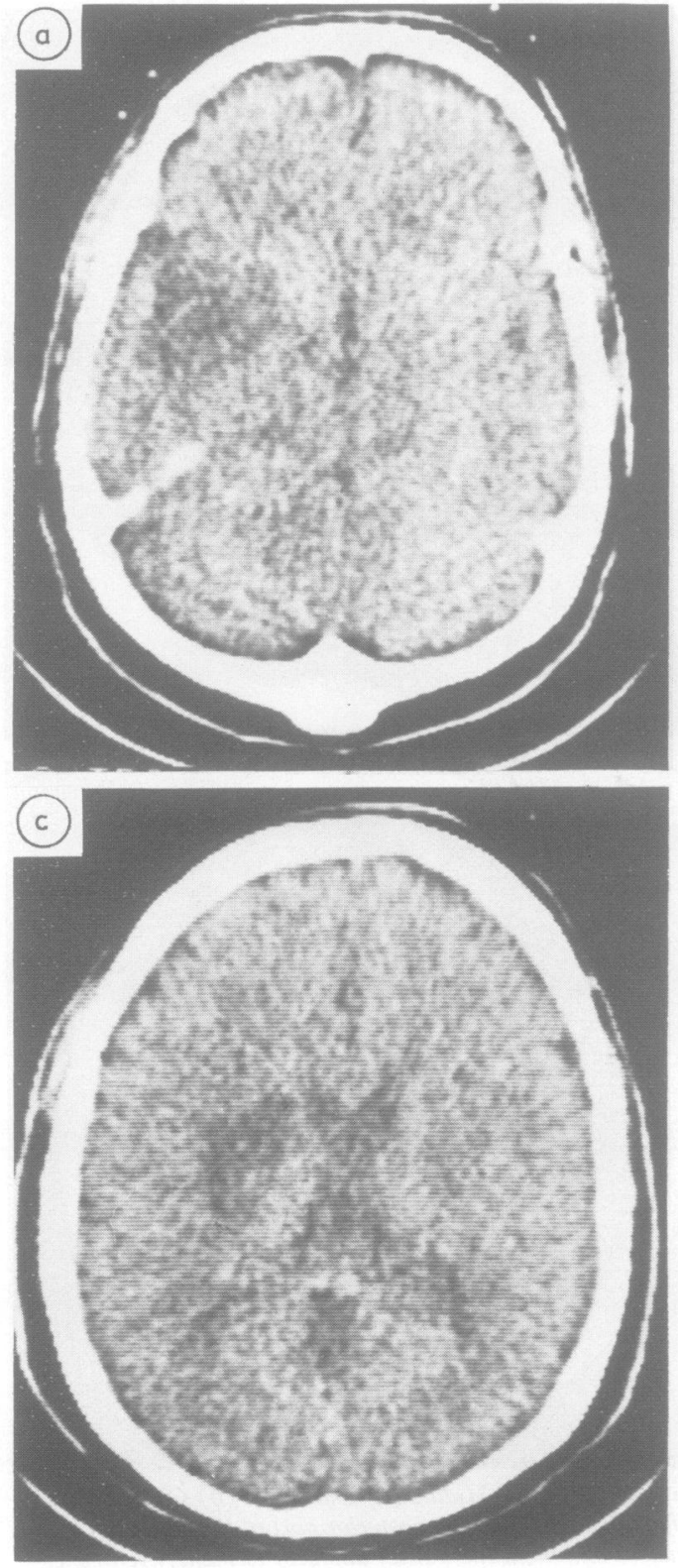

was alert, complained of headache, and had a right-sided hemiparesis and fluent aphasia.

Seventeen days after the stroke, verbal comprehension was defective for complex commands only. She was anomic, but could repeat sentences. Her right limbs were mildly paretic.

Twenty five days after the stroke, she was apraxic on the movement imitation test (44/70). Requested to make the sign of the cross, she raised her left hand and did nothing.

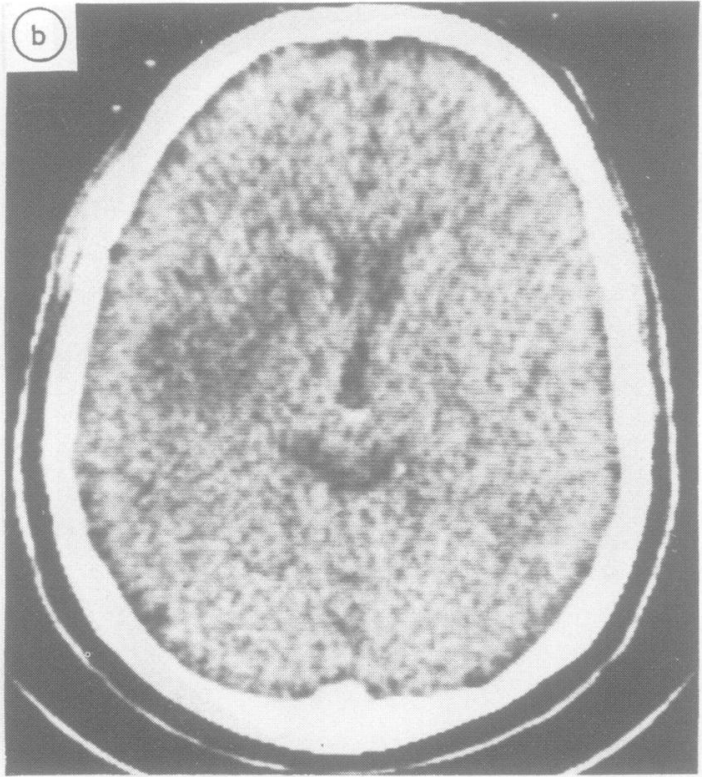

Fig 4 (Case 4). Inferior (a), middle (b) and upper (c) CT scan slice. The infarct involves the left basal ganglia, but spares the parietal and frontal cortex and the subjacent white matter.

Prompted by verbal cues, such as "Father, Son and Holy Ghost," she marked four points on her breast, starting from the bottom. Requested to pantomime a person playing the violin, she moved her closed fist up and down; to catch flies, she opened and closed her hand; and to say "no" with the finger, she moved her open hand forward and backward. There was no oral apraxia. Object utilisation was not tested. By the time of discharge one month after the stroke, the signs of limb apraxia had disappeared. 
A week after the stroke, a CT scan showed a haematoma destroying the left thalamus and abutting on the posterior limb of internal capsule. It was present at the lower, middle and upper slices (fig 5).

The other nine cases did not show apraxia on formal testing, although in the first 10 days of disease patient 6 had been found severely impaired in imitating oral and limb movements. Their clinical picture, apraxia test scores and CT findings are summarised in table 2.

\section{Discussion}

No textbook of neurology or neuropsychology mentions the possibility that limb apraxia may result from deep nuclei damage. We have been able to find in the old literature only one case report. Von Monakow (ref 18, page 520) describes a patient who had marked difficulty in eating and dressing by himself, which was attributed to apraxia. Necropsy showed a tubercle destroying the postero-ventral part of the lenticular nucleus, the posterior limb of the internal capsule and the subthalamic region. In evaluating the dearth of positive findings, it must be kept in mind that apraxia is a symptom that seldom disrupts everyday activity and may, consequently, escape the patient and examiner's attention unless purposefully investigated. The same caveat applies to lack of reference to apraxia in recent papers reporting CT scan evidence of basal ganglia and thalamic damage in cases of aphasia, in most of which it is not explicitly stated that praxis was assessed. Studies satisfying this requirement do in fact mention a few positive cases, although details are usually lacking, as the focus of investigation was language.

Following thalamic vascular damage, limb apraxic difficulty was reported by Cappa and Vignolo ${ }^{19}$ in one of their three patients, by Bogliun et $\mathrm{al}^{20}$ in one of their five patients and by Graff-Radford $e t a^{21}$ in all of their three patients. Among 15 patients with left putaminal or thalamic haemorrhage ${ }^{3}$ six showed a mild apraxia, consisting in the use of a body part as object. Nine patients with an infarct or haemorrhage involving the left putaminal-capsular region were investigated ${ }^{4}$ with the Boston Diagnostic Aphasia Examination, which also includes an oral and limb apraxia battery. Limb apraxia was found in all the patients whose lesion encroached upon the posterior part of the region, while it was more rare in this as well as in another study ${ }^{5}$ when damage was confined to the antero-superior part. It is apparent from this review that cases of apraxia associated with subcortical lesion have in fact been noticed by previous investigators, but they were given no emphasis and lacked details.

We believe that the evidence provided by our five patients is unequivocal. These patients performed well below normal controls, regardless of the manner
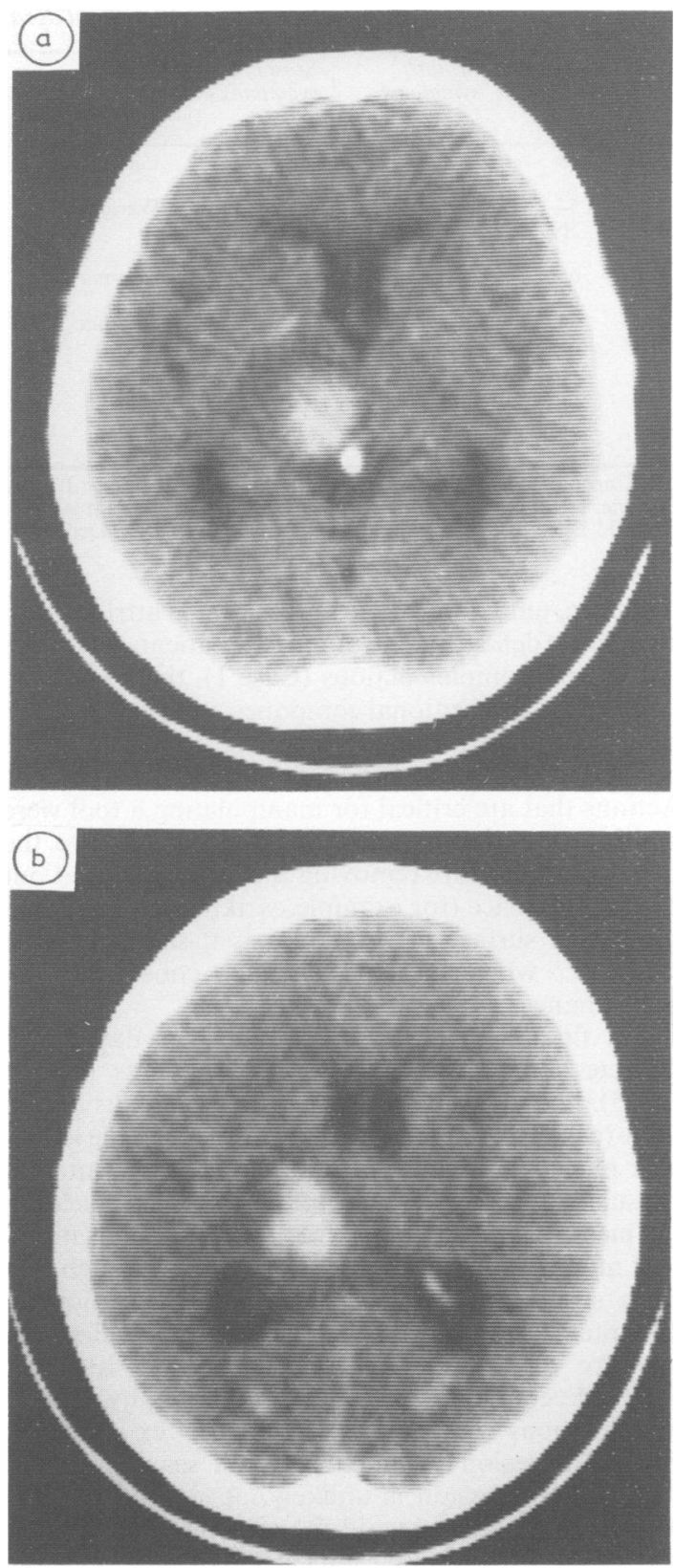

Fig 5 (Case 5). Middle (a) and superior (b) CT scan slice. The haematoma destroys the left thalamus and the posterior limb of the internal capsule.

in which the gesture organisation was tested, whether by imitation, or pantomimes, or with the use of actual objects. In all of these conditions, test administration required a minimum of verbal instructions and it is, 
Table 2 Patients with deep nuclei damage and without apraxia

\begin{tabular}{|c|c|c|c|c|c|c|c|c|}
\hline \multirow[t]{2}{*}{ Case No. } & \multirow[t]{2}{*}{ Age (yr) } & \multirow{2}{*}{$\begin{array}{l}\text { Motor } \\
\text { symptoms }\end{array}$} & \multirow{2}{*}{$\begin{array}{l}\text { Sensory } \\
\text { symptoms }\end{array}$} & \multirow[t]{2}{*}{ Aphasia } & \multicolumn{3}{|c|}{ Apraxia scores } & \multirow{2}{*}{ CT findings } \\
\hline & & & & & Imit. & Pantom. & Use of object & \\
\hline 6 & 48 & +++ & + & Global & $53 / 72$ & & & Infarct: $\mathrm{HCN}, \mathrm{ICa}, \mathrm{LN}$ \\
\hline $\begin{array}{l}7 \\
8\end{array}$ & $\begin{array}{l}54 \\
56\end{array}$ & $\begin{array}{l}+++ \\
\text { Ataxic } \\
\quad \text { Hemipar. }\end{array}$ & - & $\begin{array}{l}\text { Wernicke } \\
-\end{array}$ & $\begin{array}{l}59 / 72 \\
59 / 72\end{array}$ & & $40 / 40$ & $\begin{array}{l}\text { Haematoma: } \mathrm{HCN}, \mathrm{ICa}, \mathrm{LN} \\
\text { Haematoma: ICp and } \\
\text { periventricular CR }\end{array}$ \\
\hline $\begin{array}{r}9 \\
10 \\
11 \\
12\end{array}$ & $\begin{array}{l}65 \\
65 \\
54 \\
65\end{array}$ & $\begin{array}{l}+ \\
++ \\
+ \\
+ \\
\text { Ataxic } \\
\quad \text { Hemipar. }\end{array}$ & $\begin{array}{l}+ \\
- \\
-\end{array}$ & $\begin{array}{l}\text { Anomia } \\
\overline{\text { Anomia }} \\
-\end{array}$ & $\begin{array}{l}60 / 72 \\
63 / 72 \\
70 / 72 \\
71 / 72\end{array}$ & $\begin{array}{l}33 / 40 \\
32 / 40 \\
36 / 40\end{array}$ & $\begin{array}{l}40 / 40 \\
39 / 40 \\
40 / 40\end{array}$ & $\begin{array}{l}\text { Infarct: posterior Th } \\
\text { Infarct: periventricular CR } \\
\text { Infarct: LN, ICp } \\
\text { Infarct: upper section of } P \text { and ICp }\end{array}$ \\
\hline 13 & 69 & $\begin{array}{l}\text { Ataxic } \\
\text { Hemipar. }\end{array}$ & + & - & $66 / 72$ & $39 / 40$ & $40 / 40$ & Infarct: ICp \\
\hline 14 & 49 & ++ & - & - & $65 / 72$ & $36 / 40$ & $40 / 40$ & Infarct: $P$, ICp \\
\hline
\end{tabular}

CR: Corona Radiata; HCN: Head of the Caudate Nucleus; ICa: Anterior limb of the Internal Capsule; ICp: Posterior limb of the Internal Capsule; LN: Lenticular Nucleus; P: Putamen; Th: Thalamus.

+: Mild Deficit; + +: Moderate Deficit; +++ : Severe Deficit; $-:$ No Deficit.

therefore, unlikely that the failure can be attributed to an aphasic deficit. In one of the two patients who were tested with complex actions (Case 1), there was also evidence of an ideational component that exacerbated her defective performance, since the errors she made pointed to a defective cognition of how to use objects. Actions that are critical for manipulating a tool were omitted (for example, inserting the shackle into the padlock hole before removing the key) or carried out in a wrong place (for example, striking the match on the plastic surface of the table) as if she lacked the idea of what basic elements constitute the performance.

The finding that apraxia results from damage to discrete subcortical areas (in two patients (case 1 and 5) most of the lesion was in the thalamus and in three (cases $2,3,4$ ) most of the lesion was in the lenticular nucleus and the posterior limb of the internal capsule) suggests the participation of deep nuclei in the mechanisms that subserve gestural organisation.

It might be argued that cortical areas, though free from structural damage, were in fact functionally disrupted, as a consequence either of the effects of pressure or of the depressed metabolic rate that positron emission computed tomography (PET) investigations ${ }^{22-24}$ have shown to extend well beyond the lesion documented by CT scan. However, cortical compression is unlikely, at least in patients with thalamic damage and the evidence from studies carried out in aphasics ${ }^{23}$ indicates that while patients with cortical lesions have marked metabolic depression in the thalamus and caudate, patients with subcortical lesions have only mild cortical changes. Admittedly, the issue can be settled only by PET investigations comparing the cortical metabolic depression of patients with deep lesions with and without apraxia.

Virtually the entire cerebral cortex has connections with the caudate and putamen and although there are definite topographic relationships, no single part of the neostriatum is under the exclusive influence of a given cortical area; ${ }^{25}$ in particular, it has been established ${ }^{26}$ that cortical areas that are strongly connected project to the same caudate areas. Large and medium sized cells of the caudate and putamen send efferents to the globus pallidus, whence connections are established through the ansa lenticularis and the fasciculus lenticularis with the ventral anterior and the ventro-lateral nuclei of the thalamus. The output of the latter is to area 4, that of the former to area 6 and the entire prefrontal lobe.

The contribution of the basal ganglia to motor performance has been variously interpreted, but still defies a univocal definition, ${ }^{27}$ mainly because it has proved difficult to find an animal model of the findings provided by human syndromes, a drawback that particularly applies to apraxia, since this is a symptom specific to man. Apraxia is not easily distinguishable from akinesia in degenerative diseases primarily affecting basal ganglia. However, a recent study ${ }^{28}$ based on quantitative measurements, suggest that Parkinsonian patients show specific mild impairment in executing gestural pantomimes and in imitating non-symbolic hand positions. The impairments could not be attributed to elementary motor deficits and suggested that these patients have problems with praxis. Obviously, the consequences of an abrupt disease, such as stroke, are much more disruptive and likely to bring out true apraxia deficits. It may also be of relevance in this context to recall that a bilateral increase in basal ganglia blood flow has been reported ${ }^{29}$ associated with the execution of a complex finger sequence, like opposing thumb to fingets.

In conclusion, present data suggest that the classical structural substrate for lesions causing 
apraxia $^{11-14}$ must be enlarged to encompass a basal ganglia-thalamus-cortex loop. The arcuate fascicle and the other long cortico-cortical fibre bundles can no longer be considered the only routes used by the brain to transmit to the premotor cortex the motor programmes devised by the posterior association areas, and a crucial, though as yet unspecified role must be assigned to the basal ganglia and the thalamus. ${ }^{30}$

Further elucidation would be made easier if the lesions associated with apraxia had been clearly distinguishable from those found in negative cases. As to striatal ganglia, there is evidence in the present data that damage to the entire lenticular nucleus and the body of the caudate (Cases 2 and 4 ) is needed to produce a clear-cut apraxic picture. However, the infarct causing apraxia in Case 3 was confined to the posterior part of the putamen and the posterior limb of the internal capsule, while a haematoma involving most of the lenticular and caudate nuclei (Case 7) did not cause apraxia. Merely capsular lesions with anterosuperior extension are only found among negative cases. As for thalamic involvement, damage was confined to posterior nuclei in the negative patient (Case 9), while it extended more rostrally in the two positive cases (Cases 1 and 5).

Although CT enjoys great popularity as a means of relating neuropsychological disorders to the locus of lesion, its failure to show damage to a given area must be evaluated with caution and the last word must be left to pathological studies. Present findings are offered in the hope that they will alert neurologists and neuropsychologists to the need for carefully assessing execution of gesture also in patients with lesions localised in the deep structures of the left hemisphere.

This research was supported by a CNR grant to Dr Ennio De Renzi.

\section{References}

${ }^{1}$ Hier DB, Davis KR, Richardson EP, et al. Hypertensive putaminal hemorrhage. Ann Neurol 1977;1:152-9.

${ }^{2}$ Walshe TM, Davis KR, Fisher M. Thalamic hemorrhage: A computed tomographic-clinical correlation. Neurology (Minneap) 1977;27:217-22.

${ }^{3}$ Alexander MP, Lo Verme SR. Aphasia after left hemispheric intracerebral hemorrhage. Neurology (Minneap) 1980;30:1193-202.

${ }^{4}$ Naeser MA, Alexander MP, Helm-Estabrooks N, et al. Aphasia with predominantly subcortical lesion sites. Description of three capsular/putaminal aphasia syndromes. Arch Neurol 1982;39:2-14.

${ }^{5}$ Damasio A, Damasio H, Rizzo M, et al. Aphasia with nonhemorrhagic lesions in the basal ganglia and inter- nal capsule. Arch Neurol 1982;39:15-20.

${ }^{6}$ Puel M, Demonet D, Cardebat D, et al. Aphasies souscorticales. Etude neurolinguistique avec scanner $\mathrm{X}$ de 25 cas. Rev Neurol (Paris) 1984;140:695-710.

${ }^{7}$ Watson RT, Heilman KM. Thalamic neglect. Neurology (Minneap) 1979;29:690-4.

${ }^{8}$ Healton EB, Navarro C, Bressman S, et al. Subcortical neglect. Neurology (NY) 1982;32:776-8.

${ }^{9}$ Schott B, Laurent B, Mauquière F, et al. Negligence motrice par hematome thalamique droit. Rev Neurol (Paris) 1981;137:447-55.

${ }^{10}$ Laplane D, Escourolle R, Degos JD, et al. La negligence d'origine thalamique. Rev Neurol (Paris) 1982;138: 201-11.

${ }^{11}$ Liepmann H. Apraxie. Ergebn Gesamt Med 1920;1: 516-43.

${ }^{12}$ Geschwind N. The apraxias. Neural mechanisms of disorders of learned movements. Am Sci 1975;63:188-195.

${ }^{13}$ Heilman KM. Apraxia. In: Heilman KM, Valenstein E. (eds.) Clinical Neuropsychology. New York, Oxford University Press, 1977:159-85.

${ }^{14}$ Faglioni P, Basso A. Historical perspectives on neuroanatomical correlates of limb apraxia. In: Ray EA, Neuropsychological Studies of Apraxia and Related Disorders, Amsterdam, North Holland publishing Company 1985:23-44.

${ }^{15}$ Matsui T, Hirano A. An Atlas of the Human Brain for Computerized Tomography. Stuttgart, Fischer 1978.

${ }^{16}$ De Renzi E, Motti F, Nichelli P. Imitating gestures. A quantitative approach to ideomotor apraxia. Arch Neurol 1980;37:6-10.

${ }^{17}$ Guenther WG. Tolerance intervals for univariate distributions. Naval Res Logistic $Q$ 1972;19:309-333.

${ }^{18}$ Von Monakow C. Die Lokalisation im Grosshirn. Wiesbaden, Bergmann, 1914:520-2.

${ }^{19}$ Cappa SF, Vignolo LA. "Transcortical" features of aphasia following teft thalamic hemorrhage. Cortex 1979;15:121-9.

${ }^{20}$ Bogliun C, Sanguineti I, Tagliabue M, et al. Aspetti semeiologici di lesioni talamiche circoscritte. Studio clinico-tomodensitometrico. Riv Pat Nerv Ment 1982;103:153-61.

${ }^{21}$ Graff-Radford NR, Eslinger PJ, Damasio AR, et al. Nonhemorrhagic infarction of the thalamus: behavioural, anatomic and physiologic correlates. Neurology (Cleveland) 1984;34:14-23.

${ }^{22} \mathrm{Kuhl}$ DE, Phelps ME, Kowell AP, et al. Effects of stroke on local cerebral metabolism and perfusion: Mapping by emission computed tomography of FDG and NH. Ann Neurol 1980;8:47-60.

${ }^{23}$ Metter EJ, Riege WH, Hanson WR, et al. Comparison of metabolic rates, language and memory in subcortical aphasia. Brain Lang 1983;19:33-47.

${ }^{24}$ Metter EJ, Riege WH, Hanson WR, et al. Correlation of glucose metabolism and structural damage to language function in aphasia. Brain Lang 1984;21:187-207.

${ }^{25}$ Grofova I. Extrinsic connections of the neostriatum. In Divac I, Oeberg RGE (eds) The Neostriatum, Oxford, Pergamon Press, 1979:37-51.

${ }^{26}$ Yeterian EH, Van Hoesen GW. Cortico-striate projections in the Rhesus monkey: the organization of certain cortico-caudate connections. Brain Res 
1978;139:43-63.

${ }^{27}$ Divac I, Oeberg RGE. Current conceptions of neostriatal functions. History and evaluation. In: Divac I, Oeberg RGE. (eds). The Neostriatum, Oxford, Pergamon Press 1979:215-30.

${ }^{28}$ Sharpe MH, Cermak SA, Sax DS. Motor planning in Parkinson patients. Neuropsychologia 1983;21:455-62.

${ }^{29}$ Roland PE, Meyer E, Shibasaki T, et al. Regional cerebral blood flow changes in cortex and basal ganglia during voluntary movements in normal human volunteers. J Neurophys 1982;48:467-80.

${ }^{30}$ Kornhuber HH. Cerebral cortex, cerebellum and basal ganglia: An introduction to their motor functions. In: Schmitt FO, Worden FG. (eds) The Neurosciences. Third Study Program, Cambridge, The MIT Press, 1974:267-80. 